\title{
ANALISA DAN DESAIN SISTEM INFORMASI PENJUALAN BARANG BERBASIS OBJECT ORIENTED PADA CV. ZONA INTERNATIONAL PEOPLE
}

\author{
Rusdan Hadi $^{1)}$, Lis Suryadi ${ }^{2)}$ \\ ${ }^{1}$ Sistem Informasi, Fakultas Teknologi Informasi, Universitas Budi Luhur \\ 1,2 Jl. Raya Ciledug, Petukangan Utara, Kebayoran Lama, Jakarta Selatan 12260 \\ E-mail : 1212520124@budiluhur.ac.id ${ }^{1)}$, lis.suryadi@budiluhur.ac.id ${ }^{2)}$
}

\begin{abstract}
Abstrak
CV. Zona International People perusahaan yang usahanya bergerak dibidang penjualan ATK. Perusahaan berlokasi di Jl.Kh.Mukmin Rt,004/009,Benda tangerang, Banten. Dalam menjalankan usahanya yang berjalan saat ini dalam hal pengolahan data, CV. Zona International People menggunakan cara pengolahan data tradisional, data dicatat menggunakan tulisan tangan. Tentu kalua dilihat sepintas cara ini baik namun tidak sesuai dengan perkembangan jaman padahal pesaing sudah terlebih dahulu beralih dari cara yang tradisional ke berbasis teknologi informasi, jika tetap bertahan dengan cara seperti ini maka perusahaan akan kalah bersaing. Setelah melakukan pengumpulan data dan informasi melalui wawancara, observasi dan studi pustaka maka penulis mengurikan permasalahan yang terjadi seperi barang yang telah diretur sulit diketahui, data dan dokumen tidak tersusun dengan baik karena penyimpanan berkas yang tidak baik, informasi stock barang tidak realtime, laporan disajikan tidak tepat waktu. Setelah mempelajari masalah yang ada, solusi yang dapat diusulkan yaitu CV. Zona International People harus merubah proses pengolahan data yang ada menggunakan komputerisasi, tentunya dalam membuat sistem komputerisasi yang baik mengikuti kaidah perancangan sistem yang ada, pada penelitian ini metode untuk menganalisa data menggunakan metode berorientasi obyek dimana diagram yang digunakan seperti activity, usecase, calss diagram, sequence dibantu dengan tool Unified Modeling Language(UML).
\end{abstract}

Kata kunci: sistem informasi penjualan, CV. Zona International People,Unified Modeling Language(UML).

\section{PENDAHULUAN}

\subsection{Latar Belakang}

Penjualan merupakan suatu terpenting pada perusahaan bergerak dalam bidang perdagangan, karena dengan penjualan perusahaan berharap mendapat keuntungan yang bisa untuk melanjutkan usaha perusahaan tersebut. Untuk mendukung kegiatan sistem penjualan dibutuhkan suatu sistem terkomputerisasi agar dapat memperlancar serta mempermudah proses pengolahan data transaksi penjualan. Perusahaan yang baik tentu memiliki tujuan jangka panjang supaya pada masa yang akan datang dapat mengalami perubahan yang baik. Dengan adanya perkembangan yang semakin pesat di era globalisasi ini banyak perusahaan berlomba lomba untuk mendapatkan banyak keuntungan dengan berbagai macam kegiatan penjualan. Kegiatan perusahaan yang bisa menghasilkan keuntungan adalah penjualan dan penjualan itu bagian utama dari kegiatan usaha. Penjualan merupakan salah satu faktor terpenting dalam perusahaan. Saat ini pengolahan data masih dilakukan dengan cara manual. Dalam aktivitas penjualan tidak hanya sekedar pekerjaan menjual saja, tapi adalah dari awal bagaimana aktivitas penjualan tersebut dapat tercatat baik, bagaimana memperoleh konsumen, kemudian mengadakan pemesanan, sampai barang tersebut diterima oleh konsumen dengan puas tanpa adanya keluhan dari konsumen[1]. Kegagalan sistem manual dalam penjualan disebabkan oleh sistem tersebut tidak dikembangkan sesuai dengan perkembangan perusahaan yang dari hari ke hari bertambah pesat dan komplek. Sistem adalah kelompok yang berkaitan erat juga berhubungan satu dan lainnya, berfungsi bersama-sama untuk tercapainya tujuan tertentu[2]. Sistem manual tidak lagi bekerja secara sempurna, maka diperlukan peranan komputer yang dapat melaksanakan pengolahan berbagai transaksi penjualan. Berikut permasalahan yang terjadi dari hasil pengumpulan data dan informasi melalui wawancara, observasi dan studi pustaka dari dokumen yang ada, permasalahan pertama stock barang tidak otomatis update, pengolahan dokumen menjadi lebih lama, sering salah, pencarian dokumen lama, informasi disajikan tidak tepat waktu dan belum sesuai keinginan pimpinan. Penelitian yang dilakukan oleh penulis memiliki manfaat agar mempercepat waktu dalam penjualan buku dan menjadikan informasi perhitungan lebih efektif dan efesien akan memberikan pelayanan terhadap penjualan menjadi lebih efektif. 


\subsection{Penelitian Sebelumnya}

Dibawah ini beberapa literatur penelitian sebelumnya:

a. Victor Nicolas (2013), judul karya ilmiah perancangan sistem informasi penjualan dan pemesanan produk berbasis web pada CV. [3]

b. Pebrianto (2011), judul karya ilmiah perancangan sistem informasi penjualan berbasis web dengan metodologi RAD pada PT. Simtex Mechatronic Indojaya.[4].

\section{METODE PENELITIAN}

Metodologi penelitian adalah langkah-langkah yang digunakan pada penelitian ini menjadi terstruktur. Adapun langkah-langkah yang dilakukan untuk mencapai tujuan dari peneltian ini adalah seperti Gambar 1.

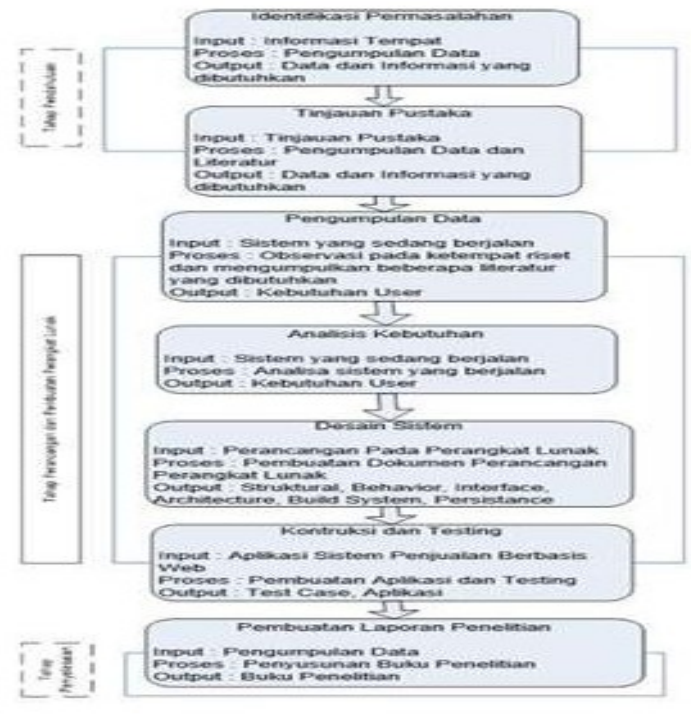

Gambar 1. Diagram alur penelitian

\subsection{Identifikasi masalah}

Tahap awal penelitian ini dimulai dari perumusan masalah yang dijadikan objek penelitian. Rumusan masalah dilakukan dengan cara melihat terlebih dahulu kondisi yang sebenarnya di lapangan. Selanjutnya menentukan tujuan penelitian. Tujuan penelitian adalah sasaran yang ingin diwujudkan.

\subsection{Tinjauan Pustaka}

Tinjauan pustaka dilakukan guna mencari literatur pendukung penelitian ini. Pada tahap ini dijelaskan dengan mengunjungi dan mempelajari website atau situs-situs yang berhubungan dengan sistem penjualan berbasis web, teori-teori, untuk pengumpulan data dan tools yang digunakan oleh penulis. Serta dijelaskan mengenai metode yang digunakan.

\subsection{Metode Pengumpulan Data}

Ada dua cara yaitu dengan melakukan observasi suatu tempat dan literatur. Observasi digunakan untuk memperoleh dan mengumpulkan data yang dibutuhkan. Cara yang dilakukan melalui Observasi yaitu melihat langsung ketempat riset untuk mengumpulkan data. Berikutnya dari Studi literatur, studi literatur yaitu mengumpulkan data yang berasal dari penelitian sbelumnya, atau sumber lain seperti buku, jurnal..

\subsection{Analisis Kebutuhan}

Analisis kebutuhan aplikasi dilakukan untuk mengetahui kebutuhan pengguna terhadap aplikasi yang dikembangkan. Hal ini perlu dilakukan agar aplikasi yang dikembangkan sesuai dengan kebutuhan pengguna. Dibagian ini juga dijelaskan siapa saja yang akan menggunakan aplikasi ini, dan informasi apa saja yang digunakan oleh mereka. Untuk pengembangan metode yang digunakan yaitu model SDLC (System Development Life Cycle) pengembangan atau rekayasa sistem informasi (software enginering).

\subsection{Desain Sistem}

Pada tahap ini penulis membuat perancangan sistem yang akan di usulkan. Perancangan tersebut meliputi, merancang tampilan user, merancang basis data untuk sistem tersebut agar manajemen file yang ada lebih teratur, kemudian yang terakhir adalah merancang koding program dari suatu informasi.

\subsection{Implementasi Sistem dan Testing}

Implementasi dan testing adalah proses untuk memastikan bahwa aplikasi yang dikembangkan bebas dari kesalahan, dilakukan testing (uji coba) pada aplikasi tersebut. Pada tahap ini juga akan dilakukan evaluasi terhadap hasil penelitian yang dilakukan. Evaluasi dilakukan mencakup evaluasi hasil dan manfaat cara dengan membandingkan hasil yang didapatkan dengan kebutuhan pengguna.

\subsection{Pembuatan Laporan Penelitian}

Langkah terakhir dari penelitian ini adalah membuat laporan Penelitian. Laporan ini berisi halhal yang dikerjakan selama penelitian dan hasil yang didapatkan pada saat melakukan penelitian.

\section{HASIL DAN PEMBAHASAN}

Diagram ishikawa disebut juga diagram sebab akibat atau fishbone diagram adalah diagram yang digunakan untuk mengidientifikasi sebab serta 
akibat dari suatu masalah[5]. Dapat dilihat pada Gambar 2.

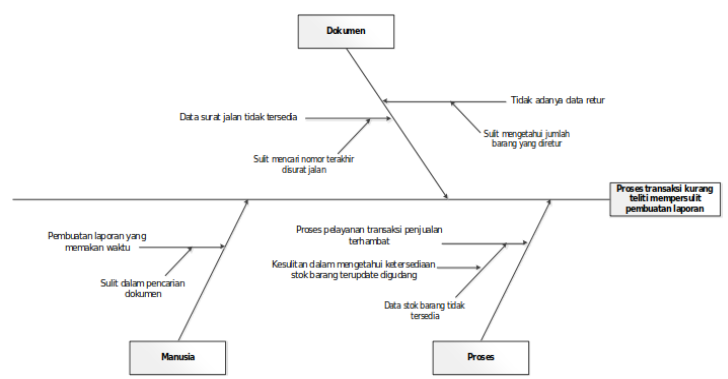

Gambar 2. Fishbone Diagram

\subsection{Activity Diagram}

Activity diagram sebagai gambaran aliran kerja/aktivitas sebuah sistem di perangkat lunak[6].

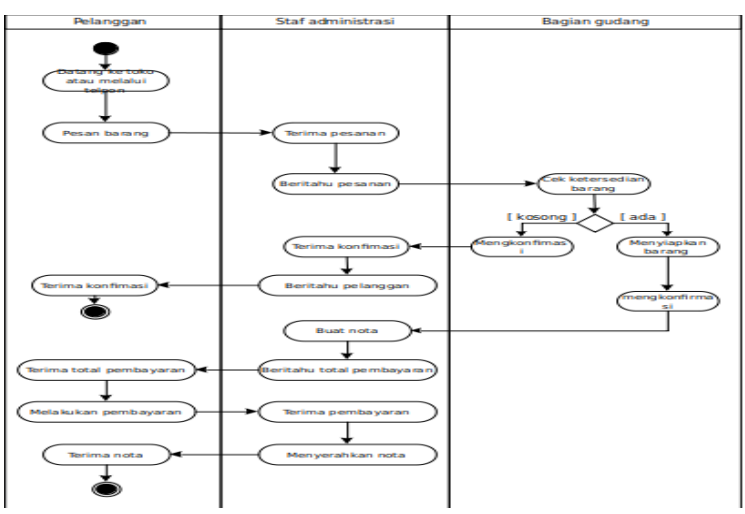

Gambar 3. Activity Diagram Proses Penjualan barang

Pada gambar 3 menggunakan proses penjualan barang ketika pelanggan memesan barang yang akan dibeli dengan cara datang langsung atau melalui telpon, untuk pemesanan yang melalui telpon biasanya pelanggan yang sudah menjadi langganan tetap dan pembelian dalam jumlah besar, staf administrasi akan memberitahu pesanan ke bagian gudang untuk mengecek barang yang dipesan, apabila tidak tersedia staf administrasi akan mengkonfirmasikan kepada pelanggan bahwa barang saat ini sedang kosong. Apabila barang tersedia bagian Gudang akan menyiapkan barang dan staf administrasi akan konfirmasi ke pelanggan untuk membuat nota dan pelanggan membayar sesuai harga total barang yang dipesan kemudian staf administrasi akan menyerahkan nota sebagai bukti pemesanan dan pembayaran.

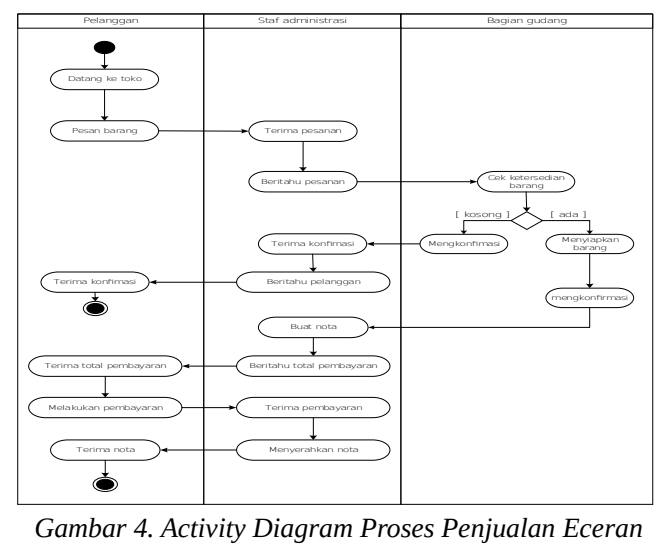

Pada gambar 4 menggunakan proses penjualan eceran Selain melayani penjualan barang dalam jumlah besar dengan pelanggan tetap, Cv. Zona International People melayani juga penjualan dengan eceran untuk pelanggan yang hanya membeli barang sesekali saja dan dalam jumlah kecil, pelanggan yang akan membeli barang datang langsung ke tempat, lalu menanyakan barang yang akan di beli, staff administrasi menyiapkan barang, pelanggan membayar barang lalu dibuatkan nota, nota diserahkan ke pelanggan.

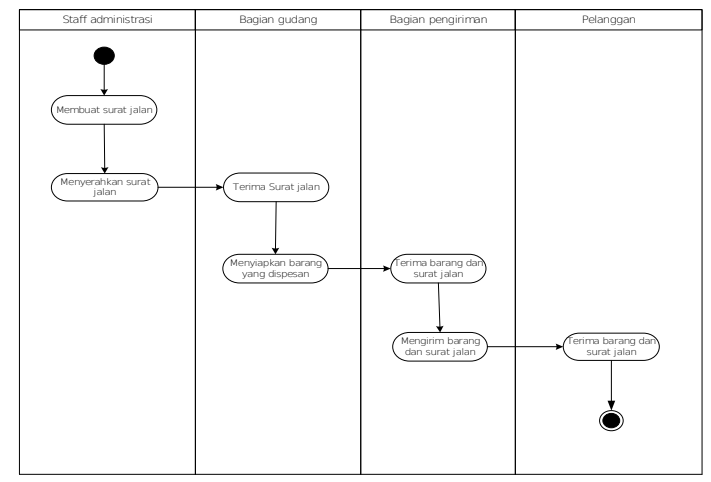

Gambar 5. Activity Diagram Pengiriman

Pada gambar 5 menggunakan proses pengiriman. Pengiriman barang hanya untuk pelanggan tetap yang membeli barang dalam jumlah besar, Setelah konsumen melakukan pembayaran, Staff Administrasi membuatkan Surat Jalan dan menyerahkannya ke bagian gudang untuk disiapkan barangnya. Setelah barang sudah siap bagian Gudang akan menyerahkan surat jalan ke bagian pengiriman kemudian bagian pengiriman akan mengirimkan barang kepada pelanggan. 


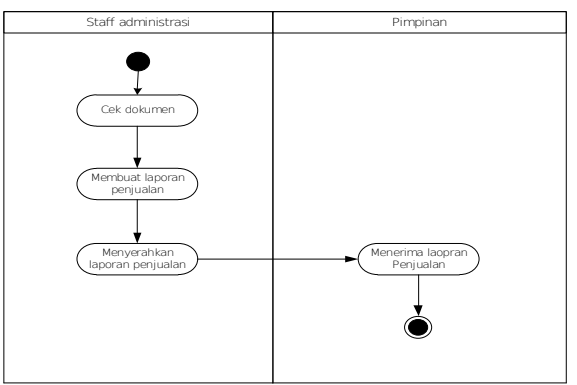

Gambar 6. Activity Diagram Proses Laporan

Pada gambar 6 menggunakan proses laporan. Dari dokumen yang ada, Staf administrasi membuat laporan penjualan dan diserahkan kepada pemilik untuk diarsipkan serta untuk memantau kegiatan penjualan pada Cv. Zona International People.

\subsection{Use Case Diagram}

Merupakan pemodelan untuk kelakuan yang dibuat[6].

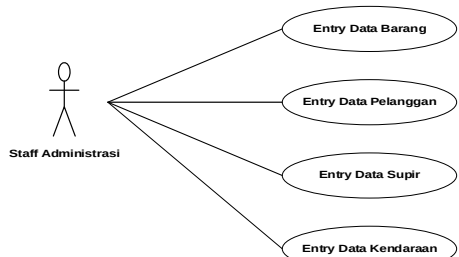

Gambar 7. Use Case Diagram Master

Pada gambar 7 terdapat usecase entry data barang entry data pelanggan entry data supir entry data kendaraan.

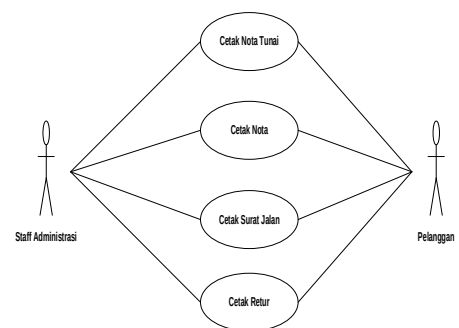

Gambar 8. Use Case Diagram Transaksi

Pada gambar 8 terdapat usecase transaksi cetak nota tunai cetak nota cetak surat jalan dan cetak retur.

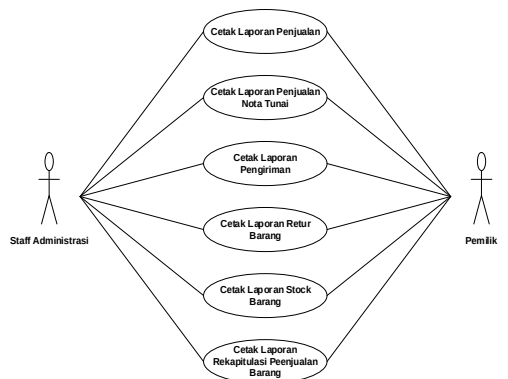

Gambar 9. Use Case Diagram Proses Laporan

Pada gambar 9 terdapat usecase cetak laporan penjualan, cetak leporan penjualan nota tunai, cetak laporan pengiriman, cetak laporan retur barang, cetak laporan stok barang, cetak laporan rekapitulasi penjualan barang.

\subsection{Class Diagram}

Class diagram merupakan gambaran suatu class yang saling berhubungan antara class lainnya didalam sebuah sistem dan saling berkolaborasi dalam mencapai tujuan [6].

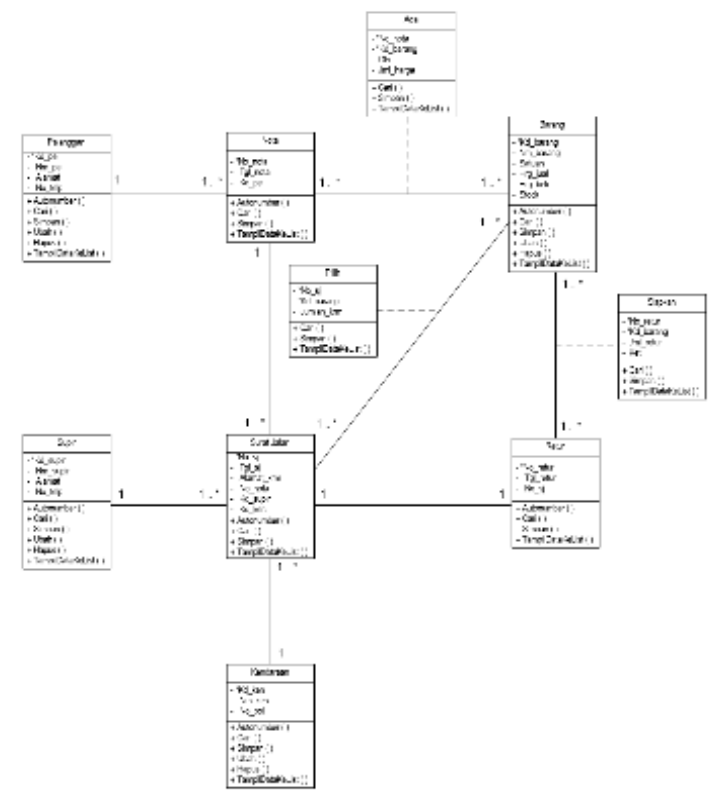

Gambar 10. Entity Class

\subsection{Tampilan Layar}

Fom data pelanggan di klik oleh bagian staff administrasi lalu data pelanggan tampil sesuai dengan rancangan data. Data pelanggan di masukan dengan benar, selain memasukan data, dapat juga di lakukan perubahan data, penghapusan data.Gambar fom terlihat pad gambar 11 . 


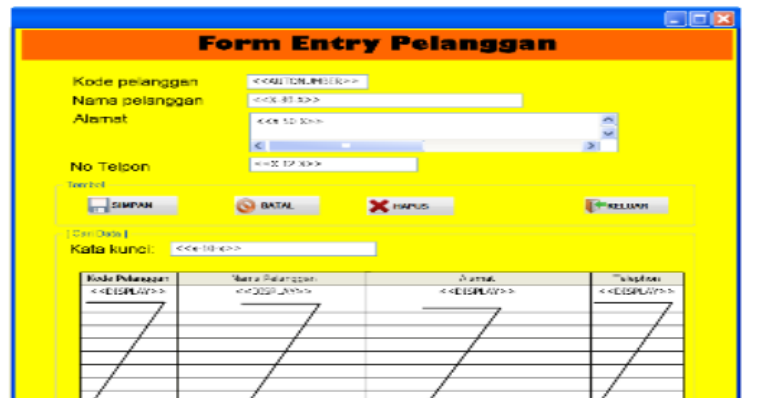

Form data Barang diklik oleh bagian Administrasi lalu kode Barang tampil berurutan sesuai dengan rancangan kode. Data barang dimasukan dengan benar. Selain memasukan data, dapat juga dilakukan perubahan data, mpenghapusan data. Gambar form terlihat pada gambar 12.

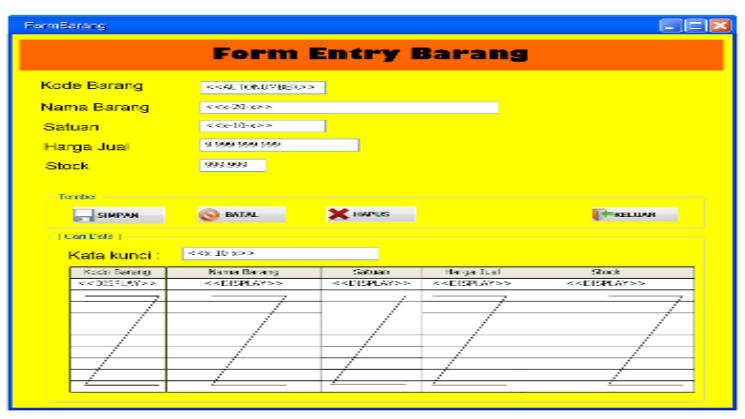

Gambar 12. Form Entry Data Barang

Form cetak nota untuk menginput pembelian barang yang dibeli pelanggan bagian admistrasi membuka form dan mengklik akan tampil secara autonumber kemudian tgl nota akan muncul secara otomatis lalu administrasi data barang kemudian bagian administrasi mengimput jumlah pesan kemudian tampil jumlah harga dan mengklik tombol cetak. Gambar fom terlihat pada gambar 13.

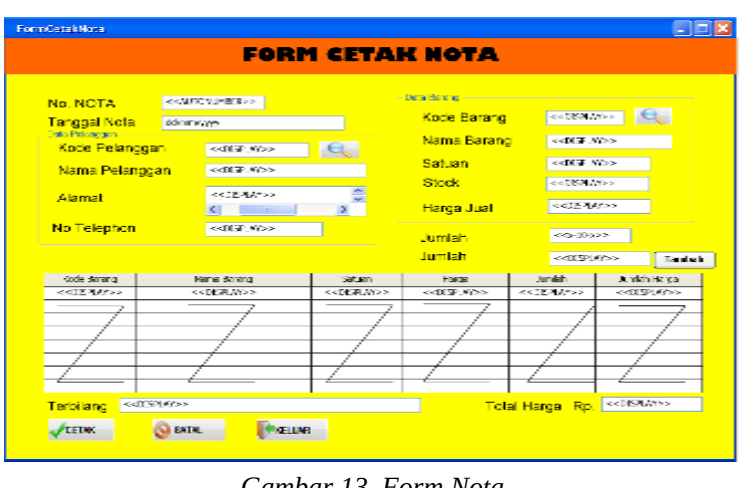

Form cetak nota tunai untuk menginput pembelian barang yang dibeli pelanggan bagian admistrasi membuka form dan mengklik akan tampil secara autonumber kemudian tgl nota akan muncul secara otomatis lalu administrasi data barang kemudian bagian administrasi mengimput jumlah pesan kemudian tampil jumlah harga dan mengklik tombol cetak. Gambar form terlihat pada gambar 15.

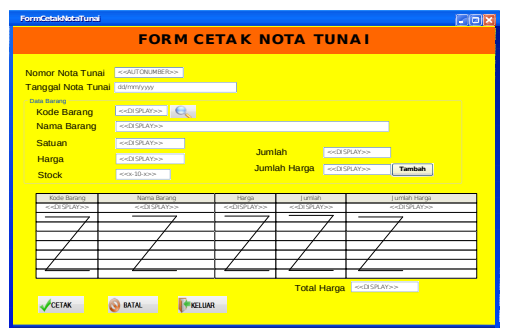

Gambar 14. Form Nota Tunai

Fom surat jalan di klik administrasi kemudian nomor tampil secara autonumber lalu tgl keluar secara otomatis terisi oleh sistem kemudian administrasi mencari data supir,kendaraan dan data barang lalu administrsi mengimput jumlah krim dan tambah kemudian administrasi mengklik tombol cetak setelah proses simpan otomatis. Gambar form terlihat pada gambar 16 .

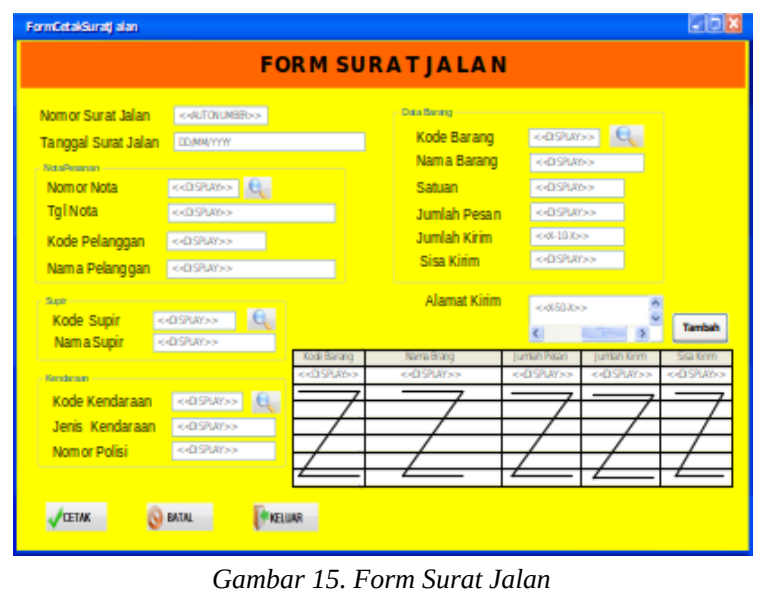

Fom retur di klik administrasi kemudian nomor tampil secara autonumber lalu tgl keluar secara otomatis terisi oleh sistem kemudian administrasi mencari data surat jalan dengan mengklik tombol cari maka akan tampil data surat jalan,lalu administrasi mencari data barang dengan memilih data di dalam ListView kemudian administrasi mencetak.Gambar fom terlihat pada gambar 17. 


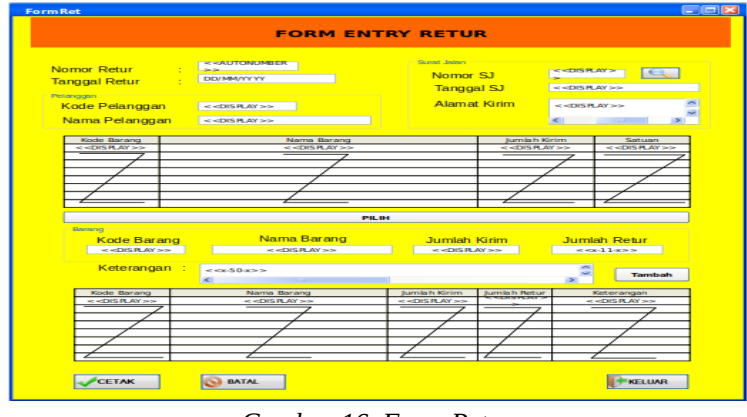

Gambar 16. Form Retur

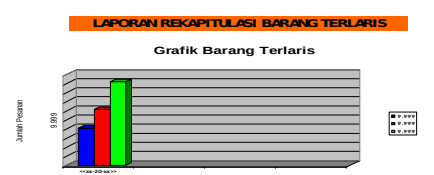

Nemen bumangs
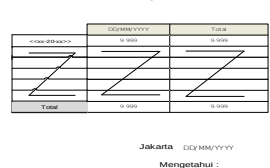

Gambar 17. Cetakan Laporan Rekap Barang Terlaris

\subsection{Sequence Diagram}

Gambar 24, Sequence diagram entry data pelanggan menjelaskan urutan yang dilakukan oleh aktor pada sequence ini

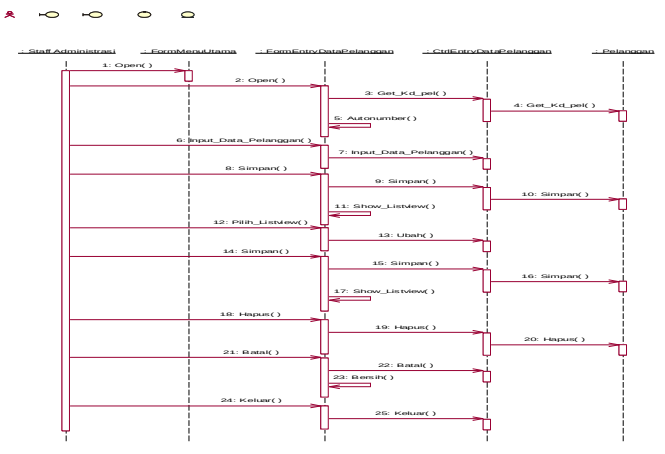

Gambar 18. Sequence Diagram Entry Data Pelanggan

\section{KESIMPULAN}

Terakhir yang dapat disampaikan pada hasil penelitian ini adalah sebagai berikut:

a. Setelah sistem diimplementasikan, stock barang akan otomatis update, ini karena menggunakan fungsi yang ada di DBMS yaitu triger

b. Pengolahan data akan lebih cepat, kesalahan perhitungan akan hilang karena perhitungan sudah dilakukan oleh sistem lalau informasi yang disajikan ke piimpinan akan tepat waktu dan akurat

\section{DAFTAR PUSTAKA}

[1] Alma, Buchari Manajemen Pemasaran dan Pemasaran Jasa. Bandung: Alfabeta. 2012.

[2] Mulyadi Sistem Akuntansi Edisi 4. Jakarta: Salemba Empat. 2016.

[3] Viktor Nicolas Nore. Perancangan Sistem Informasi Penjualan dan Pemesanan Produk Berbasis Web. Universitas Widyatama, Bandung. 2013.

[4] Pebriyanto, Sistem Informasi Penjualan Berbasis Web dengan Metodologi RAD. Universitas Islam Negeri Syarif Hidayatullah. Jakarta. 2011.

[5] Agitya, Lingga. Eksplorasi Metodologi SDLC. Sistem Informasi UNIKOM. 2013.

[6] Rosa, A.S dan M. Shalahudin. Menggunakan UML. Bandung: Informatika. 2014. 